Vol. 2 No. 2 Juli 2019

ISSN 2614-2775

e-ISSN 2621-8143


Surnal @lmu Xeolahragaan

Diterbitkan Oleh:

Program Studi Pendidikan Olahraga

Fakultas Keguruan dan Ilmu Pendidikan

Universitas PGRI Palembang

\begin{tabular}{|c|c|c|c|c|c|}
\hline Jurnal & Volume & Nomor & Halaman & Palembang & ISSN/e-ISSN \\
\hline IIalaman Oahrayg Ninsantarata & 2 & 2 & $97-197$ & 2019 & $\begin{array}{c}2614-2775 / \\
2621-8143\end{array}$ \\
\hline
\end{tabular}


Halaman Olahraga Nusantara (Jurnal Ilmu Keolahragaan)

P-ISSN 2614-2775

Volume 2, No. 2, Januari 2019

E-ISSN 2621-8143

\section{DAFTAR ISI}

Hasil Penelitian

Halaman

Penerapan Model Permainan Rounders Yang Dimodifikasi Terhadap Kemampuan Gerak Dasar Murid Sd Negeri Paccinongan Kabupaten Gowa

- Benny B, M.Rachmat Kasmad

Pelaksanaan Kegiatan Belajar Mengajar Pendidikan Jasmani di Sekolah Dasar Inklusi

- Bambang Gatot Sugiarto

Pengaruh Metode Latihan Terhadap Daya Tahan Fisik Siswa Ekstrakurikuler Sepak Bola Sma N 2 Tanjung Raja

- Mutiara Fajar.

Survei Minat Member Yang Mengikuti Fitness Pada Pusat Kebugaran Kota Palembang

- Hengki Kumbara.

Peningkatan Pengaruh Latihan Kelincahan Terhadap Kemampuan Menggiring Bola Pada Siswa Sma Negeri 3 Samarinda

- Ruslan, Nurjamal

Penerapan Permainan Dengnan Media Swiss Ball Untuk Meningkatkan Kelentukan Lower Back (Pada Mahasiswa Kop Aerobic Gymnastics Universitas Negeri Jakarta)

- M Dian Susanto, Sri Nuraini $141-153$

Patrol Multiguna Sebagai Alternatif Media Pembelajaran Tolak Peluru Di Smp Negeri 1 Sei Balai Kabupaten Batu Bara Tahun Ajaran 2017/2018

- Joko Priono $154-166$ 
Kecerdasan Gerak Dalam Pendidikan Jasmani

- Hilda Oktriyeni....................................................................... 167-176

Analisis Kesalahan Tendangan Atlet Pencak Silat Universitas PGRI Palembang

- Bayu Iswana............................................................................ 177-185

Pengaruh Metode Pembelajaran Dan Kriteria Layanan Bantuan:

Meningkatkan Gerak Dasar Lompat Jauh Gaya Jongkok Siswa Tunagrahita Ringan Pada Pembelajaran Penjasorkes SLB PKK Bandar Lampung

- Rachmi Marsheilla Aguss.............................................................. 186-197 


\title{
PENERAPAN MODEL PERMAINAN ROUNDERS YANG DIMODIFIKASI TERHADAP KEMAMPUAN GERAK DASAR MURID SD NEGERI PACCINONGAN KABUPATEN GOWA
}

\author{
Oleh : Benny B, M.Rachmat Kasmad \\ (Dosen Universitas Negeri Makassar)
}

\begin{abstract}
Abstrak
Penelitian ini bertujuan untuk mengetahui tentang Penerapan model permainan rounders yang dimodifikasi terhadap kemampuan gerak dasar Murid SD Negeri Paccinongan Kabupaten Gowa. Metode penelitian yang dilakukan dalam penelitian ini adalah metode eksperimen, dengan jumlah sampel sebanyak 30 (tiga puluh) murid kelas V (lima) SD, yang diperoleh melalui teknik total sampling. Kemudian penelitian dilakukan dengan menggunakan alat tes yaitu tes lempar sasaran, tes lompat jauh tanpa awalan, tes keseimbangan, dan tes kelincahan sekaligus sebagai sumber data awal dan data akhir penelitian. Dari hasil pre test diperoleh hasil kemampuan awal siswa sebesar 42,87, dan setelah diberikan perlakuan (permainan rounders yang dimodifikasi), maka kemampuan akhir siswa sebesar 54,71. Dari data tersebut diperoleh nilai Variabel X1 dengan rata-rata sebesar 5145 dan nilai Variabel X2 dengan rata-rata sebesar 6565. Kemudian data tersebut dianalisis dengan menggunakan rumus uji statistika, yaitu uji normalitas, homogenitas, dan uji t. Penelitian ini berlangsung selama 16 kali pertemuan. Dari hasil analisis data diatas, menunjukkan bahwa ada peningkatan kemampuan gerak dasar siswa setelah diberikan model perlakuan permainan rounders yang dimodifikasi maka penelitian menyatakan bahwa model permainan rounders yang dimodifikasi berpengaruh secara signifikan terhadap kemampuan gerak dasar Murid SD Negeri Paccinongan Kabupaten Gowa.
\end{abstract}

Kata Kunci: Permainan, Modifikasi, Rounders, Gerak Dasar

\section{IMPLEMENTATION OF MODIFIED ROUNDERS GAME MODEL ON BASIC MOVEMENT MOTION ABOUT PACCINONGAN STATE ELEMENTARY SCHOOL, GOWA REGENCY}

\begin{abstract}
This study aims to learn about the application of the rounders game model that is suggested to the basic motion abilities of Paccinongan Elementary School Elementary School students in Gowa Regency. The research method carried out in this study is a research method, with a total sample of 30 (thirty) fifth grade students (five) elementary schools, which were obtained through total sampling techniques. Then the research was carried out by using test kits, namely the target throwing test, long jump test without prefix, balance test, and agility test as well as the initial data source and final data of the study. From the results of the pre test, the results of the students' initial abilities were 42.87, and after round training was given, the final ability of students was 54.71. From these data
\end{abstract}


obtained the value of Variable X1 with an average of 5145 and the value of Variable X2 with an average of 6565. Then the data was analyzed using statistical statistical tests, namely the test for normality, homogeneity, and $t$ test. This research took place during 16 meetings. From the results of the analysis of the data obtained, it shows that there is an increase in the student's ability to move after giving a round game model that supports the research that proves a rounded game model that is related to the basic mobility ability of Paccinongan Elementary School Students in Gowa Regency.

Keywords: Games, Mods, Rounders, Basic Motion

\section{A. PENDAHULUAN}

Kemampuan gerak sangat di tentukan oleh kemampuan gerak dasar yang dimiliki seseorang. Sesuai dengan aktivitas yang di tekuni dan dilakukan seorang anak.Penguasaan kemampuan gerak dasar menjadi tonggak untuk mengembangkan dan meningkatkan keterampilan di cabang olahraga. Hal ini akan membantu anak dalam menguasai dasar-dasar keterampilan pada cabang olahraga.

Untuk meningkatkan salah satu tujuan pendidikan jasmani yaitu perkembangan gerak maka perlu dilakukan aktivitas-aktivitas permainan dalam bentuk berbagai cabang olahraga.Dalam permainan olahraga terdapat berbagai unsur gerakan-gerakan yang kompleks. Gerakan-gerakan tersebut mengarah kepada unsur kondisi fisisk seperti kekuatan, daya tahan, kelentukan, kelincahan, keseimbangan dan koordinasi. Sehingga anak yang sering melakukan aktivitas olahraga dengan sendirinya kemampuan gerak dasar yang dimilikinya akan mengalami peningkatan.

Permainan rounders merupakan salah satu dari cabang olahraga bola kecil dimana dalam permainan ini terdapat unsur gerak seperti lari, melompat, melempar, memukul dan sebagainya, ini menunjukkan bahwa permainan rounders jika sering dimainkan oleh anak maka akan dapat meningkatkan kemampuan gerak dasar yang dimilikinya.

Penerapan permainan rounders yang dimodifikasi di Sekolah Dasar Negeri Paccinongan Kab.Gowa bertujuan untuk melatih para siswa menguasai teknikteknik dasar permainan rounders yang benar sehingga kesalahan yang sering 
dilakukan tidak menjadi kebiasaan.Di samping itu juga diharapkan dapat meningkatkan kemampuan gerak dasar siswa karena dalam permainan rounders terdapat gerakan-gerakan yang mengarah pada ketepatan, kelincahan, kelentukan dan keseimbangan.

Berdasarkan uraian tersebut, peneliti tertarik meneliti tentang " Model Permainan Rounders yang Dimodifikasi Terhadap Kemampuan Gerak Dasar Siswa SD Negeri Paccinongan Kabupaten Gowa".

\section{B. Metode Penelitan}

Penelitian Dilaksanakan di SD Negeri Paccinongan Kab.Gowa, Subyek penelitian adalah Siswa kelas VSD Negeri Paccinongan Kab.Gowa.Waktu pelaksanaan penelitian pada awal bulan Januari sampai Juni 2019.

Metode penelitian ini adalah Eksperimen, Sebelum melakukan perlakuan latihan terlebih dahulu diambil data pre-test dan setelah dilakukan perlakuan latihan kemudian diambil data post-test untuk menemukan informasi tentang pengaruh permainan rounders yang dimodifikasi terhadap kemampuan gerak dasar bagi siswa kelas V Sekolah Dasar Negeri Paccinongan Kab.Gowa.

Bentuk rancangan penelitian adalah Pre-test dan post- test (pre-test and post-test one group design).Adapun desain penelitian sebagai berikut :

Tabel 1. Desain Penelitian

\begin{tabular}{|c|c|c|}
\hline Pre-test & Perlakuan/ Latihan & Post test \\
\hline $\begin{array}{l}\mathrm{T}_{1}=\text { (Test Kemampuan } \\
\text { Gerak Dasar) } \\
\text { 1. Tes melempar sasaran } \\
\text { 2. Tes lompat jauh tanpa } \\
\text { awalan } \\
\text { 3. Tes Keseimbangan } \\
\text { 4. Tes Kelincahan ( lari } \\
\text { zig-zag) }\end{array}$ & $\begin{array}{l}\text { X= Permainan Rounders } \\
\text { yang dimodifikasi } \\
\text { Program yang diberikan } \\
\text { setiap perlakuan/ } \\
\text { latihan: } \\
\text { - Pemanasan } \\
\text { - Latihan teknik dasar } \\
\text { permainan rounders } \\
\text { - Bermain rounders yang } \\
\text { dimodifikasi } \\
\text { - Pendinginan }\end{array}$ & $\begin{array}{l}\mathrm{T}_{2}=\text { ( Test Kemampuan } \\
\text { Gerak dasar) } \\
\text { 1. Tes melempar sasaran } \\
\text { 2. Tes lompat jauh tanpa } \\
\text { awalan } \\
\text { 3. Tes Keseimbangan } \\
\text { 4. Tes Kelincahan ( lari zig- } \\
\text { zag) }\end{array}$ \\
\hline \multicolumn{3}{|l|}{ Ket. } \\
\hline
\end{tabular}


Teknik Pengumpulan data yang digunakan untuk mengukur kemampuan gerak dasar yang dikemukakan oleh Don R. Kirkendall, dkk (1980 : 324).

Adapun tes kemampuan gerak dasar siswa SD sebagai berikut :

Tes melempar sasaran

a. Tujuan : Mengukur Ketepatan

b. Alat/ fasilitas : 1). Bola kasti 2). Dinding yang ditandai kotak sasaran dengan jarak kotak sasaran 3,1 meter. Kotak tersebut dibagi menjadi 3 bagian, 3). Formuli test dan alat tulis, 4). Kapur dan cat.

c. Pelaksanaan : 1) Sikap Permulaan, siswa berdiri didepan sasaran dengan jarak 3,1 meter, 2). Gerakan, ada aba-aba siap bola kasti tersebut siap untuk dilempar ke arah kotak sasaran yang ditandai, kotak sasaran itu ada bagianbagian lagi yaitu kotak kecil, kotak sedang dan kotak besar, yang masingmasing mempunyai poin, yakni kotak kecil bernilai 3 poin, sedang 2 poin dan besar 1 poin.

d. Penilaian : Pada waktu melakukan lemparan salah satu atau kedua kaki tidak boleh menginjak atau melewati garis maka lemparan tersebut dianggap tidak sah dan tidak diberi angka, lemparan dihitung sejak bola lepas. Diberikan 15 kali kesempatan berturut-turut.Penilaian hasil lemparan yang dilakukan 15 kali berturut-turut.

Tes lompat jauh tanpa awalan

a. Tujuan : Mengukur power otot tungkai

b. Alat/ fasilitas : 1). Bak pasir dan papan tumpu, 2) formulir tes, alat tulis dan meteran.

c. Pelaksanaan : 1) Sikap permulaan, siswa di papan tolakan kemudian kaki ditekuk. 2) Gerakan, ada aba-aba siap kedua kaki ditekuk lalu lompat sejauh-jauhnya. 3) siswa diberi 3 kali kesempatan berturut-turut.

d. Penilaian : hasil yang dicatat ialah jarak yang terjauh yang dicapai siswa dalam centimeter $(\mathrm{cm})$. 
Tes keseimbangan

a. Tujuan : mengukur keseimbangan statis

b. Alat/ fasilitas : 1) Balok ukuran 2 inci, 2) balok ukuran 1 inci, dan 3) formulir tes dan alat tulis

c. Pelaksanaan : 1) Sikap permulaan, salah satu kaki diletakkan diatas balok, kedua tangan dipinggang. 2) gerakan dilakukan dengan mata terbuka, salah satu kaki diatas balok berukuran 2 inci dan setelah itu dilakukan lagi diatas balok 1 inci, dilakukan selama 10 detik dengan mata tertutup.

d. Penilaian : lama tester mempertahankan sikap tersebut dalam satuan detik untuk mata terbuka dan mata tertutup.

Tes kelincahan (lari Zig-Zag)

a. Tujuan : mengukur kelincahan

b. Alat/ Fasilitas : 1) 4 buah kun, 2) Formulir tes dan alat tulis, stop watch.

c. Pelaksanaan : 1) Sikap permulaan, siswa berada di titik start, 2) Gerakan, ada aba-aba siap siswa berlari melalui rintangan yang telah ditentukan hingga finish dengan jarak 1,5 meter.

d. Penilaian : Dengan menghitung berapa banyak kun yang dicapai dalam hitungan 20 detik.

Tabel 2. Nilai Tes Kemampuan Gerak Dasar Usia 9-12 Tahun

\begin{tabular}{|c|c|c|c|c|c|c|}
\hline $\begin{array}{c}\text { Jenis } \\
\text { Kelam } \\
\text { in }\end{array}$ & $\begin{array}{c}\text { Lempar } \\
\text { Sasaran } \\
\text { (jumlah) }\end{array}$ & $\begin{array}{c}\text { Lompat } \\
\text { Jauh Tanpa } \\
\text { Awalan }\end{array}$ & $\begin{array}{c}\text { Keseimbang } \\
\text { an statis } \\
\text { (detik) }\end{array}$ & $\begin{array}{c}\text { Kelincaha } \\
\text { n (detik) }\end{array}$ & Nilai & Keterangan \\
\hline Putra & $\begin{array}{l}22 \text { keatas } \\
18 \mathrm{~s} / \mathrm{d} 21 \\
12 \mathrm{~s} / \mathrm{d} 17 \\
03 \mathrm{~s} / \mathrm{d} 11 \\
01 \mathrm{~s} / \mathrm{d} 03\end{array}$ & $\begin{array}{c}134 \text { keatas } \\
103 \mathrm{~s} / \mathrm{d} 133 \\
75 \mathrm{~s} / \mathrm{d} 102 \\
65 \mathrm{~s} / \mathrm{d} 74 \\
50 \mathrm{~s} / \mathrm{d} 64\end{array}$ & $\begin{array}{l}28 \text { keatas } \\
21 \mathrm{~s} / \mathrm{d} 27 \\
14 \mathrm{~s} / \mathrm{d} 20 \\
08 \mathrm{~s} / \mathrm{d} 13 \\
05 \mathrm{~s} / \mathrm{d} 07\end{array}$ & $\begin{array}{l}28 \mathrm{ke} \text { atas } \\
21 \mathrm{~s} / \mathrm{d} 27 \\
14 \mathrm{~s} / \mathrm{d} 20 \\
08 \mathrm{~s} / \mathrm{d} 13 \\
04 \mathrm{~s} / \mathrm{d} 07\end{array}$ & $\begin{array}{c}90+ \\
75 \\
50 \\
25 \\
1\end{array}$ & $\begin{array}{c}\text { Sangat baik } \\
\text { Baik } \\
\text { Cukup } \\
\text { Kurang } \\
\text { Sangat kurang }\end{array}$ \\
\hline Putri & $\begin{array}{c}22 \mathrm{ke} \text { atas } \\
18 \mathrm{~s} / \mathrm{d} 21 \\
12 \mathrm{~s} / \mathrm{d} 17 \\
03 \mathrm{~s} / \mathrm{d} 11 \\
01 \mathrm{~s} / \mathrm{d} 03\end{array}$ & $\begin{array}{c}129 \text { keatas } \\
99 \mathrm{~s} / \mathrm{d} 128 \\
73 \mathrm{~s} / \mathrm{d} 98 \\
63 \mathrm{~s} / \mathrm{d} 72 \\
45 \mathrm{~s} / \mathrm{d} 62\end{array}$ & $\begin{array}{l}22 \text { keatas } \\
16 \mathrm{~s} / \mathrm{d} 21 \\
12 \mathrm{~s} / \mathrm{d} 15 \\
08 \mathrm{~s} / \mathrm{d} 11 \\
03 \mathrm{~s} / \mathrm{d} 07\end{array}$ & $\begin{array}{l}22 \mathrm{ke} \text { atas } \\
16 \mathrm{~s} / \mathrm{d} 21 \\
12 \mathrm{~s} / \mathrm{d} 15 \\
08 \mathrm{~s} / \mathrm{d} 11 \\
04 \mathrm{~s} / \mathrm{d} 07\end{array}$ & $\begin{array}{c}90+ \\
75 \\
50 \\
25 \\
1\end{array}$ & $\begin{array}{c}\text { Sangat baik } \\
\text { Baik } \\
\text { Cukup } \\
\text { Kurang } \\
\text { Sangat kurang }\end{array}$ \\
\hline
\end{tabular}




\section{HASIL PENELITIAN DANPEMBAHASAN}

Pada penelitian ini dilakukan test awal (pre test) dan tes akhir ( post test) kemampuan gerak dasar yang terdiri dari lempar sasaran, lompat jauh tanpa awalan, keseimbangan dan kelincahan. Dimana hasil test dari seluruh siswa adalah sebagai berikut:

Tabel 3. Pre Test

\begin{tabular}{|l|l|l|l|l|}
\hline No. & $\begin{array}{l}\text { Lempar } \\
\text { Sasaran }\end{array}$ & $\begin{array}{l}\text { Lompat Jauh } \\
\text { Tanpa Awalan }\end{array}$ & Keseimbangan & Kelincahan \\
\hline Jumlah & 472 & 2308 & 344 & 408 \\
\hline $\begin{array}{l}\text { Rata- } \\
\text { rata }\end{array}$ & 15,73 & 76,93 & 11,47 & 13,60 \\
\hline
\end{tabular}

Tabel 4. Post Test

\begin{tabular}{|c|c|c|c|c|}
\hline No. & $\begin{array}{l}\text { Lempar } \\
\text { Sasaran }\end{array}$ & $\begin{array}{l}\text { Lompat Jaun } \\
\text { Tanpa } \\
\text { Awalan }\end{array}$ & Keseimbangan & Kelincahan \\
\hline Jumlah & $\mathbf{5 6 4}$ & $\mathbf{2 3 6 0}$ & $\mathbf{4 4 8}$ & $\mathbf{4 5 8}$ \\
\hline $\begin{array}{l}\text { Rata- } \\
\text { rata }\end{array}$ & $\mathbf{1 8 , 8 0}$ & $\mathbf{7 8 , 6 7}$ & $\mathbf{1 4 , 9 3}$ & 15,27 \\
\hline
\end{tabular}

Dari data pre test dan post test diatas diperoleh nilai variabel $\mathrm{X}_{1}$ (pre test) dan $\mathrm{X}_{2}$ (post test) kemampuan gerak dengan jumlah sebagai berikut:

Tabel 5. Rata Rata

\begin{tabular}{|l|c|r|r|r|r|l|}
\hline & $X_{1}$ & $X_{2}$ & $X_{2}$ & $X_{2}{ }^{2}$ & $B$ & $B^{2}$ \\
\hline Jumlah & 5145 & 911925 & 6565 & 1463225 & 1420 & 81300 \\
\hline Rata-rata & 171,5 & & 218,83 & & 47,33 & 2710 \\
\hline
\end{tabular}

Dari nilai $\mathrm{X}_{1}$ dan $\mathrm{X}_{2}$ diatas dilakukan uji normalitas untuk mengetahui apakah data tersebut berdistribusi normal atau tidak. Setelah dialakukan uji normalitas maka diperoleh pada data pre test L-hitung $=-0,0454$ dan L- tabel= 0,188 diperoleh dari uji liliefors dengan taraf nyata $\alpha=0,05$. Maka dapat disimpulkan bahwa L-hitung $(-0,0454)<$ L-tabel $(0,188)$, maka data berdistribusi normal. Dan data yang diperoleh pada data post test L-hitung $=-0,0599$ dan Ltabel $=0,188$ diperoleh dari uji liliefors dengan taraf nyata $\alpha=0,05$ (dapat dilihat 
pada lampiran 4). Maka dapat disimpulkan bahwa L-hitung $(-0,0599)<$ L-tabel $(0,188)$, maka data berdistribusi normal.

Setelah pengujian normalitas maka diadakan uji homogenitas dengan cara varian terbesar dibagi varian terkecil maka diperoleh $F_{\text {hitung }}(1,0725)$ sedangkan $\mathrm{F}_{\text {tabel }}$ diperoleh dari Dk penyebut dan pembilang $-1=21(\alpha=0,05)$ diperoleh $\mathrm{F}_{\text {tabel }}$ $=2,09$. Diperoleh hasil $F_{\text {hitung }}(1,0725)<F_{\text {tabel }}(2,09)$ maka data hasil penelitian adalah homogen.

Berdasarkan hasil perhitungan hipotesis $t_{\text {hitung }}=9,41$ pada taraf signifikan $\alpha=0,05$ dengan $n=22$ dan harga $t_{\text {tabel }}=1,72$ (dapat dilihat pada tabel $G$ lampiran 7). Dengan membandingkan harga antara $t_{\text {hitung }}$ dan $t_{\text {tabel }}$ diperoleh $t_{\text {hitung }}(19,41)>$ $\mathrm{t}_{\text {tabel }}$ (1,72). Sehingga dapat disimpulkan bahwa permainan rounders yang dimodifikasi berpengaruh secara signifikan terhadap terhadap kemampuan gerak dasar siswa kelas V SD Negeri Paccinongan Kab.Gowa

Berdasarkan perhitungan dan pengujian hipotesis di atas menunjukkan $\mathrm{H}_{\mathrm{o}}$ ditolak dan $\mathrm{H}_{\mathrm{a}}$ diterima.Dengan demikian dapat dikatakan bahwa permainan rounders yang dimodifikasi berpengaruh secara signifikan terhadap kemampuan gerak dasar siswa kelas V SD SD Negeri Paccinongan Kab.Gowa.

\section{KESIMPULAN}

Dari hasil pengujian hipotesis maka dapat ditarik kesimpulan bahwa permainan rounders yang dimodifikasi berpengaruh secara signifikan terhadap kemampuan gerak dasar siswa kelas V SDNegeri Paccinongan Kab.Gowa.

\section{DAFTAR PUSTAKA}

Amung, Yudha 2000. Perkembangan Gerak dan Belajar Gerak. Pendidikan Nasional Direktor Jendral Pendidikan Dasar dan Menengah Bagian Proyek Penataran Guru SLTP Setara D III

Bahagia. Yoyo. 2000. Prinsip-prinsip Pengembangan dan Modifikasi Cabang Olahraga. Departemen Pendidikan Nasional Direktoran Jendral Pendidikan Dasar dan Menengah Bagian Proyek Penataran Guru SLTP Setara D-III.

Don R. Kirkendall. 1980. Measurement And Evaluation For Physical Educators. Human Kinetic Publisher, in Champing, Illinois. 
Hananto Budi Santoso, Tri. 2010. Pendidikan Jasmani Olahraga dan Kesehatan. Jakarta : Yudhistira

Hurlock. 1999. Psikologi Perkembangan. Erlangga. Jakarta

Lutan R. 1988. Belajar Keterampilan Motorik, Pengantar Teori dan Metode Jakarta, Departemen Pendidikan dan Kebudayaan Direktorat Jendral Pendidikan Tinggi Pengembangan Lembaga Pendidikan Tenaga Kependidikan.

Singer RN, (1980). Motor Learning Human Performance An Application to Motor Skill and Movement Behaviour. New York: Mc Millan Publishing Co. Inc.

Soepartono. 2000. Sarana dan Prasarana Olahraga. Jakarta, Departemen Pendidikan dan Kebudayaan. Direktur Jendral Pendidikan Dasar dan Menengah Bagian Proyek Penataran Guru SLTP setara D III

Soepartono. 2000. Metode Modifikasi. Jakarta, Departemen Pendidikan dan Kebudayaan. Direktur Jendral Pendidikan Dasar dan Menengah Bagian Proyek Penataran Guru SLTP setara D III

Sudjana. 1992. Metode Statistika. Bandung : Tarsito

Sugiyanto. 2002. Perkembangan dan Belajar Motorik. Universitas terbuka Departemen Pendidikan Nasional. Jakarta

Sukintaka. 1979. Permainan dan Metodik Buku III. Jakarta: Departemen Pendidikan dan Kebudayaan

Sukintaka. 1992. Teori Bermain. Jakarta, Departemen Pendidikan dan Kebudayaan Direktur Jendral Pendidikan Tinggi Proyek Tenaga Pendidikan.

Sunarno. A, Chairul Azmi, Benny Subadiman. (2003). Belajar Motorik. Medan Fakultas Ilmu Keolahragaan UNIMED Medan

Suyono H. (1996). Belajar Motorik. Medan FPOK IKIP

Yanuar Kiram, Phil. 1992. Belajar Motorik. Departemen Pendidikan dan Kebudayaan Direktorat Jendral Pendidikan Tinggi Proyek Pembinaan Tenaga Kependidikan 